\title{
ANTECEDENTS OF KNOWLEDGE ACQUISITION IN MICRO, SMALL AND MEDIUM ENTERPRISES
}

\author{
Bernice Korkor Gligah1*, Norzaidahwati Zaidin², Eugene Okyere-Kwakye ${ }^{3}$ \\ 1,2 Faculty of Management, University Technology Malaysia, 81310 UTM, Skudai, \\ Malaysia. \\ ${ }^{3}$ Faculty of Management, University Technology Malaysia, 81310 UTM, Skudai, \\ Malaysia. \& Faculty of Business and Management Studies, Koforidua Technical \\ University, P.O. Box KF 981 Koforidua, Ghana.
}

*Corresponding Author email: gkbernice@gmail.com bernicekorkor@graduate.utm.my Article History

\begin{abstract}
Knowledge acquisition has gained several research areas, such as human resources, marketing, finance, performance, and so forth. It has been acknowledged as an essential path for business success. While firms recognize the importance of knowledge acquisition to enhance business performance, previous literature indicates that SME's are limited in knowledge acquisition efforts corroborated by the limited research in knowledge sources. For SMEs, knowledge acquisition can be identified as a vital variable as its absence may often hamper the leverage of attaining firm objectives. The frugality of research in discussing the antecedent factors in knowledge acquisition unequivocally, in the Micro, Small and Medium Scale Enterprises is the motivation for the present study. Based on previous studies the study develops a conceptual framework to suggest a relationship between knowledge acquisition and four antecedent factors (domestic knowledge, market knowledge, technological knowledge, and environmental knowledge). A Questionnaire is proposed to collect data and Smart PLS would be used to analyze the data.

Conclusion/Recommendations: This study attempts to discuss some of the precursor variables that can affect knowledge acquisition.
\end{abstract}

Keywords: Knowledge; Knowledge Acquisition; Micro Small and Medium Enterprises (MSMEs); Manufacturing; Domestic; Market; Technological; Environmental; Knowledge-Based Theory

Abbreviations: Nil

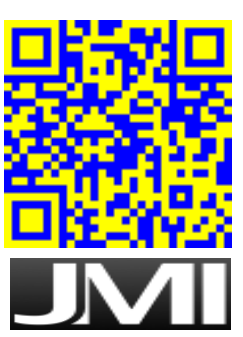

Journal of Management Info. Vol. 7 No. 2, 2020: pp. 76-91 Doi: 10.31580/jmi.v7i2.1420 www.readersinsight.net/jmi

\section{Readers /nsight}




\section{INTRODUCTION}

Micro, small and medium-sized enterprises (MSMEs) and entrepreneurial organizations in the present knowledge-based society face new strategic difficulties(Afriyie, Duo, Appiah, \& Musah, 2018). In the view of Basten and Haamann, (2018), firms need to manage issues of knowledge acquisition and ought to have the option to discover a balance among acquisition and use of knowledge activities, this is corroborated by the work of Ramaiah, (2019); he asserts that knowledge acquisition is an integral part of intellectual growth and innovation. Moreover, MSMEs' activities can significantly improve if they adopt an increasingly dynamic knowledge sourcing (X. Xie, Wang, \& Zeng, 2018; X. Xie, Zou, \& Qi, 2018). Be that as it may, for SMEs, adjusting organizational routines in the context of the knowledge-based challenge is a significant issue. As indicated by Pentina, (2018), SME characteristics often hamper the distinguishing proof and influence of resources and competencies necessary within the firm to yield new chances. Theoretically, knowledge acquisition emanates from the resource-based and knowledge-based view theories (Kaplan \& Schenkel, 2001). The resource-based view (RBV) theory views the firm as a bundle of resources framework (Wernerfelt, 1984). The RBV theory is of the view that organizations comprise of both tangible and intangible assets (Barney, 1991). This theory explains how organizational resources, tangible and intangible resources can be exploited by the firm to achieve sustainable competitive advantage. RBV indicates that a company expects to use its resources in its product design cycle to harness the resources and capabilities of companies to optimize success in product innovation (Barney, 2001; Feng \& Wang, 2013).

On the other hand, the rationale for the Knowledge-Based View Theory is an organization is an emphasis on the role of information in establishing performance and influencing it thus Knowledge Based-View aims to make the company function as smartly as possible to secure its potential and overall success and otherwise realize the best value of its knowledge assets (Curado, 2014). On the argument that knowledge is a resource to the firm, the ability of firms to fully find, absorb, manage and utilize the source of knowledge available to them both internally and externally is a panacea for the firm's success or otherwise. Thus firms that can acquire and exploit knowledge or information effectively stand a greater chance of outperforming similar firms that fail to make effective use of knowledge (Bojica \& Fuentes-fuentes, 2019; Xie, Wang, et al., 2018; Liao \& Barnes, 2015).

Knowledge, therefore, becomes a valuable resource or asset that needs to be protected by organizations through measures such as company secret and confidentiality agreements (Grant 1996). Deducing from the importance of knowledge 
acquisition to organizational success, perhaps it is worthy to understand the factors that would influence knowledge acquisition in micro, small and medium scale enterprises (MSMEs) which has been shelved. Thus the dimensions domestic knowledge (prior knowledge available to the firm and knowledge gained out of experience), market knowledge (knowledge acquired from customers and competitors), technological knowledge (knowledge acquired through the advent of technology), environmental knowledge (knowledge acquired in response to environmental issues), knowledge emanating from the Knowledge-Based View Theory are selected as antecedent factors that influence knowledge acquisition. Therefore, this study aims to discuss the influence of antecedent factors i.e., domestic, market, technological and environmental knowledge on knowledge acquisition based on the Knowledge-Based View Theory.

\section{KNOWLEDGE ACQUISITION}

Knowledge acquisition is an important practice for intellectual development and innovation (Liao \& Barnes, 2015). This includes eliciting, gathering, evaluating, modeling and validating information (Mohannak, 2014). The conception and definition of knowledge acquisition can be taken from the words of a philosopher in English, John Locke. In his view, people are born unknown; that is the human mind is "blank slate or tabula rasa" and we acquire knowledge through experience (Evangelista \& Mac, 2016). Knowledge acquisition, therefore, could be described as learning through experience and experiments. It concerns the acquisition, assimilation, adaptation, and corroboration of knowledge conceptualization, explanation, question formulation or interpretation and problem solving or reaching conclusions (Góra \& Góra, 2017). The acquisition is outlined as the capacity to gather, comprehend and gain the extraneous information fundamental for an association's tasks (Zahra and George, 2002; Johnson, 2017). Knowledge acquisition is depicted as a procedure including information gain from human specialists, books, papers, sensors or PC records (Huber, Science, Issue, \& Learning, 2014). Knowledge might be extraordinary to the difficult field or the situation tackling techniques, it might be basic information (e.g., business information) or it might be meta-knowledge (Bennet \& Bennet, n.d.). In a business setting, clients' providers' rivals and accomplices/unions are the significant wellsprings of obtaining information (He, Zhang, Tian, Tao, \& Akula, 2018).

Meanwhile, Oslo (2005), knowledge gathering encapsulates how the entity gains information from suppliers, customers or clients, competitors and open research establishments for their development practice. The information picked up from all the stakeholders might be direct or indirect (He et al., 2018). As upheld by Liao, Barnes, College, \& Carolina, 2015; Waribugo, Wilson, \& Etim, 2016, the gathered information 
that gives knowledge empowers the firm to lead its innovation practices for the product, strategy, promoting, including organizational developments. In one progressively point of view by Grant and Baden-Fuller (1995), little and medium-sized associations have little resource limit, for instance, capacities and gear, and they need to obtain new information from outside to improve their benefit at record-breaking at insignificant cost.

Deducing from the above discussion, the reasoning of knowledge is similar to knowing something and being able to reason through it with other conditions. As such, this knowledge resides in our minds and is the result of human experience and reflection. Even though there seems to be an agreement on the complexity of knowledge in their role and competencies, individuals play an important role in the acquisition of knowledge and the creation of knowledge. Nonetheless, knowledge can be sourced from various avenues either directly or indirectly (Oslo Manual, 2018).

\section{KNOWLEDGE-BASED VIEW THEORY (KBV)}

The main thrust of the knowledge-based theory is that companies function as a result of their information management capability and managing it efficiently than other types of organizational structures (Grant 1996). It relates that organizations are social entities that acquire, store and use internal knowledge, competencies, and capabilities which are essential for organizations' growth and success (Pentina, 2018). The rationale for an organization's knowledge-based viewpoint emphasizes the role of information in establishing performance and influencing it thus Knowledge-based views aim is to make the company function as smartly as possible to secure its potential and overall success and otherwise realize the best value of its knowledge assets (Curado, 2014). Knowledge is a valuable asset of the company; its proponents are of the view that knowledge is peculiar to organizations and socially complex based on the capabilities and the responsiveness are precursors to superior firm performance (Liao \& Barnes, 2015).

The theory upholds the relevance of superior coordination and integration of learning by employees within the organization (Crescenzi \& Gagliardi, 2018; Jiménez-jiménez \& Sanz-valle, 2011). The theory presents knowledge as tacit and explicit knowledge; tacit knowledge is the information or knowledge known to an individual and explicit knowledge being information known to others as well ( Nonaka 1996; Nonaka \& Lewin, 2011). Tacit knowledge which is presented as a valuable resource to an organization is costly to copy, as it is credited to an individual and be copied or learned through articulation, observation, and practice from people who possess such knowledge or skill. It is not easily documented and transmitted mainly through watching someone 
exhibiting skills and abilities. Researchers have argued that tacit knowledge can be transmitted into explicit knowledge (Huber et al., 2014). Explicit knowledge refers to information that is general to others which could be internalized knowledge (explicit knowledge available but not in use by the firm) and procedural knowledge (skills and capabilities knowledge) available for use to an organization. On the argument that knowledge is a resource to the firm, the ability of firms to fully find, absorb, manage and utilize the sore of knowledge available to them both internally and externally is a panacea for the firm's success or otherwise. Thus firms that can acquire and exploit knowledge or information effectively stand a greater chance of outperforming similar firms that fail to make effective use of knowledge. Knowledge, therefore, becomes a valuable resource or asset that needs to be protected by organizations through measures such as company secret and confidentiality agreements.

Writers have raised debates on whether the individual or the collective is the source of new knowledge of value to the firm; this they term as "locus of knowledge" whereas many have focused on a collective locus of knowledge, others (Grant 1996; Roper, Love, \& Bonner, 2017) in the minority have focused on the individual locus of knowledge. Meanwhile, studies examining firms' knowledge assets have also been on the rise (Crescenzi \& Gagliardi, 2018; Jiménez-jiménez \& Sanz-valle, 2011; Argote \& Miron-spektor, 2011). In as much as fundamentally knowledge has been seen as a resource to firms (Grant 1996; Huber 1991; Grant and Baden-Fuller, 2004; Argote \& Miron-spektor, 2011; Crescenzi \& Gagliardi, 2018 ), other perspectives have been espoused such as knowledge being something that is learned, produced and shared through a community of people; and later discussions on having highlighted on knowledge and knowing (Venkitachalam, \& Busch, 2012).

\section{KNOWLEDGE-BASED VIEW THEORY (KBV) AND KNOWLEDGE ACQUISITION}

The firm's KBV demonstrates the role of information in evaluating organizational learning through knowledge acquisition and optimizing performance. Knowledge evolves from active learning within organizations, facilitated by organizational practices and problem-solving activities and creates value from effective implementation. The firm's KBV conceptualizes organization as an institution for knowledge development and integration. Throughout knowledge based-theory, the information capital is the intangible assets of a company.in the growing knowledge economy, businesses need to produce strategic competence for value-forming competence derived from the firm's intangible assets. Intangible assets cannot be measured, are difficult to quantify, cannot be achieved instantaneously and are not easily tracked by accounting. Examples of intangible assets include know-how on 
technology, organizational culture and organizational learning (Barney, 2001; Kaplan \& Schenkel, 2001; Serrat, 2014).

Inside organizations, knowledge emerges from varied sources; experiential learning is driven by organizational processes and problem-solving exercises and generates values from its successful implementation (Stephen, Oluseye, \& Abolaji, 2017). The company's knowledge-based view conceptualizes entities as platforms for knowledge creation and integration (Mehralian, Nazari, \& Ghasemzadeh, 2018). In knowledge theory, the knowledge resource considered as intangible assets of a company. Intangible assets are not measurable, they are difficult to quantify, they are not easy to track by accounting, they need to be improved over time, and they cannot be obtained immediately, purchased or imitated and valued over intent (Hamdoun, Chiappetta Jabbour, \& Ben Othman, 2018).

The concept of knowledge acquisition is in agreement with the knowledge-based theory and the consequential results between knowledge acquisition and its progressive consequential organizational innovation synchronize with the knowledge based-theory. Based on this knowledge, differences in organizations' achievements are linked to organizational competence and capabilities in creating and deploying new knowledge. The organization is seen as the key element in the development and application of knowledge. There is, therefore, the relevance to understand how companies are generating and handling new knowledge. The need to explore ways of producing and deriving value from information assets within the organization has gained some level of attention from researchers (Anatoliivna, 2013; Mahmoud et al., 2016; Noblet, Simon, \& Parent, 2011; Wang \& Wang, 2016).

Noting that the RBV and KBV all assert to the use and application of knowledge as a firm resource in business transformation, this aspect of resource which is naturally surrounded in the firm can assist MSMEs to use knowledge as a tool to create innovative products that are unique and differentiated. It is imperative to note that companies are not working alone in the market in this relation, but are trying to take advantage of a variety of sources of knowledge which could emanate from prior knowledge, knowledge from customers and competitors, environmental and technological knowledge breakthroughs. It is important to ascertain the influence of these antecedent factors in the scope of this study, the scope, therefore, covers the following:

1. Domestic knowledge comprising of prior knowledge available and knowledge gained from experience. 
2. Market knowledge that discusses knowledge acquired from customers and knowledge sourced from competitors.

3. Technological knowledge which relates to knowledge sourced from new technological advancements.

4. Environmental knowledge which explains knowledge generated from the external market space intending to respond to environmental issues.

The rationale for choosing the above sources is strongly linked to three major reasons: the first being, their role on the collective innovation system which is well established in the prior literature in varied ways (Huber 1991). Secondly, the sources selected are definite knowledge sources representing the original individual sources of knowledge. Finally, the resulting performance characteristics of firms through learning is sourced from varied sources not only from a single dimension (Zhou, Hu, \& Shi, 2015) Based on the discussion of previous studies above, this study will examine four dimensions of knowledge acquisition adopted from literature from the works (Bojica \& Fuentesfuentes, 2019; Hailikari, Katajavuori, \& Lindblom-Ylanne, 2008; R. Hui Xie, Yuan, \& Huang, 2017). The antecedent factors will be explained in more detail in the subsequent session. Figure 2.1 below shows the components of knowledge acquisition used in this study.

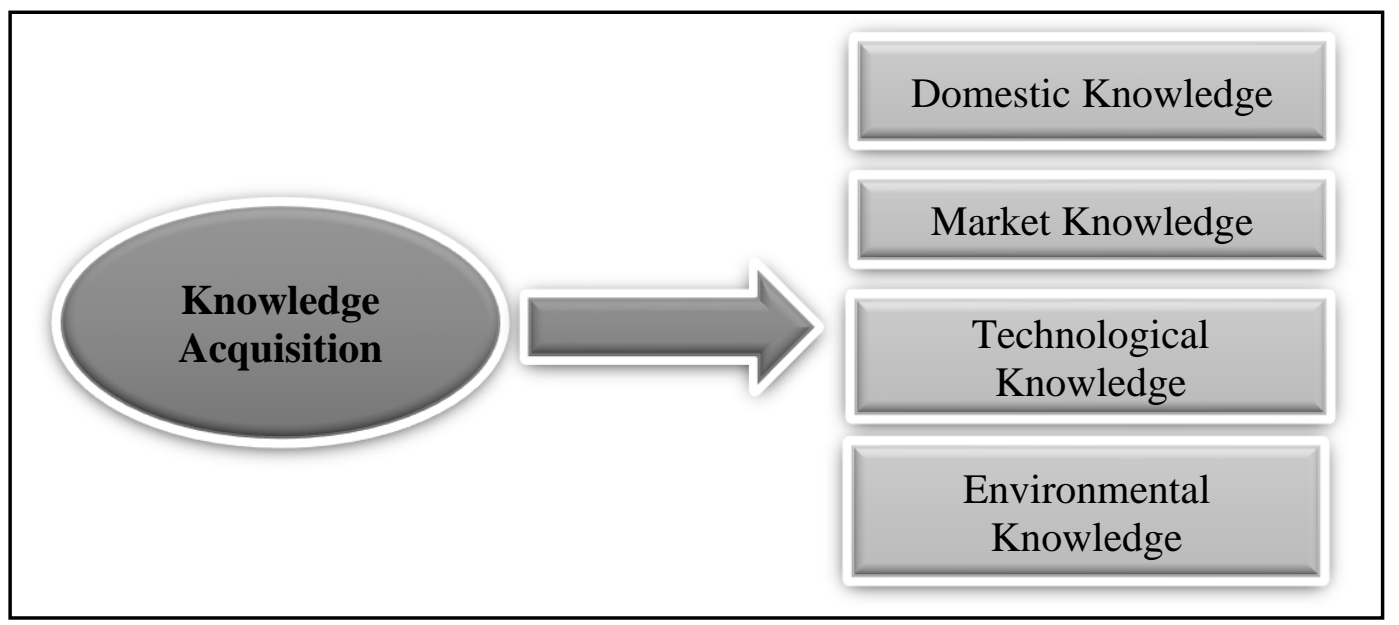

Fig. 1: KA dimensions in this study

\section{HYPOTHESES DEVELOPMENT}

\section{DOMESTIC KNOWLEDGE}

Domestic knowledge which is conceptualized in this study as prior knowledge available and knowledge gained by firms through experience has gained quite some attention in the literature (Argote \& Miron-spektor, 2011; Evangelista \& Mac, 2016; Shane, n.d.) The literature on knowledge acquisition is multidimensional, paramount among them is prior knowledge that is available at birth and learning from experience 
(Huber et al., 2014). Experience is the thing that comes to pass in the firm as it plays out its assignment (Yachin, 2018). For instance, in a manufacturing firm, the experience can be measured by the cumulative number of items produced through the experience knowledge. In the view of Argote et.al, (2003) learning starts with experience which is the principal and emerging theme in organizational learning which has been discussed in various dimensions. Argote and Todorova (2007) suggested experiential parameters, comprising social, organizational, material, spatial, and relational ones. Experience in groundbreaking activities or functions which have been constantly practiced in the earlier days can indeed be acquired (Evangelista \& Mac, 2016; Katie, Milway, \& Saxton, 2011).

Prior knowledge, regardless of whether learned from job experience, education, or other means, affects knowledge acquisition in firms ability to understand, infer, analyze and incorporate new information in ways that cannot be reproduced by those lacking the prior knowledge (Hailikari et al., 2008; Rao \& Monroe, 1988). Pazzani et al., (1989) argues that much of the continuous learning is either embedded in prior knowledge or adjusted in prior knowledge. In other words, the information presented to a firm in several forums such as conferences, workshops, training, etc. will tend to be triggered by those which possess prior knowledge (Shane, n.d.). New knowledge may enhance prior knowledge, for instance, an individual/ group of persons who may have formerly worked in different capacities and environments may have knowledge which is not available to the general public.

New knowledge, therefore, could be complemented by previous knowledge to strengthen knowledge acquisition (Shane, n.d.). In a study by Evangelista \& Mac, 2016 on the relative importance of deliberate learning, learning from experience relevant learning on export performance in smaller firms with a usable study sample of 139 manufacturing firms, the study account's that deliberate learning has a greater impact on export market learning as compared to experience accumulation. The study as well unveiled that market learning has a significant effect on export performance. The measure of Domestic knowledge is therefore seen as prior knowledge available and knowledge gained from experience, which has been linked to knowledge acquisition of firms but in a different context. In pursuance of the ongoing discussion, the study proposes that:

H01: Domestic knowledge has a positive relationship with knowledge acquisition.

\section{MARKET KNOWLEDGE}

Market-based knowledge acquisition to how the market behaves by understanding customers and competitors well to enhance firm capability in innovation (Evangelista 
\& Mac, 2016). According to them when firms interact with customers through customer inquiries, customer requests, customer preferences, complaints or series of actions leading to responses; these presents opportunity for firms to acquire/ gain knowledge likewise when firms engage with competitors over time, it accumulates both explicit and tacit knowledge.

Customers are considered as a knowledge resource available in the market to transform new product designs/ process by involving them (Storey \& Larbig, 2018), customers are getting involved in the innovation initiation process of firms by increasingly making inputs in the operations and innovation activities of firms for firms to meet the requirements and taste of the market. The use of customer knowledge has evolved in the advancement of business activities, it has increasingly become a vital issue in today's dynamic environment. The role of customers is not restricted to just the purchase of a product but the activity involved in co-creation with firms. In effect, customers are engaged in sharing their experience and knowledge between themselves and the firms. Firms can take advantage of these exchange processes in employing innovative measures to ensure firm sustainability. Meanwhile, studies on customer involvement in innovation have been inconsistent. It is worth noting that customer involvement on its own cannot guarantee success (Storey \& Larbig, 2018).

In furtherance to that, the research by Taghizadeh et al., (2018) on knowledge from the customer, for the customer or about the customer on innovation capability, studied 253 managers of 26 banks in Bangladesh, using a quantitative means, their results indicate that knowledge from customer and knowledge for the customer has a positive influence on service market performance. In furtherance to that innovation, quality has an impact on new service market performance. In a related work by Schaarschmidt \& Walsh, (2018) which focused on customer interaction in the B2B business, using a unique data set of 146 information technology and manufacturing firms, an interview was conducted which revealed that customer interaction appears beneficial to both goods and services innovation in a hybrid offerings context. The ongoing discussions lead the study to hypothesize that:

\section{Ho2: Market knowledge has a positive relationship with knowledge acquisition.}

\section{TECHNOLOGICAL KNOWLEDGE}

In the view of Song, Park, \& Park, (2017), they state that changes in SME development are dependent on new information gained through technology transfer which can and do happen yet in any different ways compared to large organizations. Small companies are much more focused on personal beliefs, with the prime motivation for survival, instead of organizational growth and innovation (Huggins, Prokop, \& Thompson, 
2017), such acts have influenced how small manufacturing firms work and their absorptive capacity being utilized.

The predicted positive relationship between technological knowledge and production or profitability measures is confirmed by several studies in strategic management and manufacturing organization economy (Subbanarasimha, Ahmad, \& Mallya, 2003; Moorthy \& Polley, 2010; Harrigan, Di Guardo, \& Cowgill, 2017). The inherent knowledge and knowledge-building capacity of a company influence the development of its new product (Liao \& Barnes, 2015). Such earlier studies found technical knowledge unidimensional, and hence explored the interaction between knowledge quantity and performance; researchers have thus argued that the depth and breadth of technological knowledge are critical for firm success (Moorthy \& Polley, 2010).

In the opinion of Subbanarasimha et al., (2003), they describe technological knowledge in terms of the depth and breadth of knowledge. The knowledge gained by a company in a technical field promotes accelerated product development as the company has a good understanding of Specific restrictions and stumbling blocks; Comprehensive interconnections between demand and technical potentials; and. R\&D which consists of searching through a specific novel and unknown directions. As a consequence, the depth of technological knowledge contributes not just to speed up the development of carefully orchestrated newer products, but also for the development of many other new products that the business may not have originally planned (Vrontis, Thrassou, Santoro, \& Papa, 2017). The range of technological knowledge includes the ability of manufacturing companies with active $R \& D$ programs to combine a broad range of technical disciplines is relevant (Schot \& Steinmueller, 2018), meanwhile, as a consequence of limited resources, companies are forced to choose the domains they would explore and to what extent. Also, Miller \& Toh, (2018) suggests that profitable product creation encompasses both core and complementary technologies.

Determining the extent of technological knowledge requires information about the different technology fields in which a firm has developed knowledge. Such information is available in patent documents which can be found in patented/licensed records (Pantano, Priporas, Sorace, \& lazzolino, 2017). Noting that technological knowledge is critical to SME's in developing products by optimizing technology, it is much more significant for small and medium-sized enterprises to have successful knowledge acquisition to leverage new technology and access new information and markets (Bojica \& Fuentes, 2012; Liao \& Barnes, 2015). The differentiating factor is a firm's ability to infuse technological knowledge. The discussion above leads the study to state that: 


\section{Ho3: Technological knowledge has a positive relationship with knowledge acquisition.}

\section{ENVIRONMENTAL KNOWLEDGE}

The business environment is the fundamental setting in which strategies are formulated, methodologies planned and actualized (Grant, 2010). Firms cannot settle on choices without understanding the environmental regulations as well as characteristics and their attributes, without which their firm may not survive (OECD, 2007; Yu \& Shen, 2020). Firms thus need to be environmentally responsive. Recent decades, specifically, have been marked by the rapid and substantial changes in the business environment, which present difficulties and opportunities to the firms (Yu \& Shen, 2020). Literature on strategy has since quite a while ago perceived the role of the business environment in the predictive analysis. The conventional SWOT and PEST models, which centers on the business environment could be used to undertake environmental analyses (Baker, n.d.).

The opportunities and threats in the SWOT reflect potential outcomes and dangers in the business environment dimensions which can be built up by examining the business condition measurements of the PEST models (Kotler \& Keller, 2012). It implies that the supervisors interpret environmental characteristics to decide how they create and execute various strategies in various situations, and actually, there is no set best arrangement (Long, Chen, Du, Oh, \& Han, 2017) leading to variations will create various outcomes (Camisón-Haba, Clemente-Almendros, \& Gonzalez-Cruz, 2019). As an outcome, the comprehension of the business environment influences knowledge acquisition as well as effects its effectiveness (Grant, 2010). Organizational routines create an environment that permits organizations to refine, expand and exploit existing abilities or develop new ones by incorporating knowledge picked up and changed through their practices (Lin, Chen, \& Su, 2017).

Cohen and Levinthal, (1990) recommend that the capacity of the organization to invest in the creation of absorptive capacity relies upon the taking in circumstances that originate from its environment. Such significant exogenous variables are demand from the market, the reach of technological opportunities, the security of protected innovation rights, and the simplicity of learning past information. The more applicable expertise is accessible to the organization and the more prominent the capacity to improve existing innovation, the greater the desire of the organization to put resources into learning and R\&D (X. Xie, Zou, et al., 2018). In this study, environmental knowledge will be discussed on the framework built around environmental structures and inferences provided, the sources and significance of the environmental change, and 
how firms obtain such information from their environments to influence the overall knowledge acquisition of firms. The study, therefore, proposes that:

\section{Ho4: Environmental knowledge has a positive relationship with knowledge acquisition.}

Table I: Table of Study Hypotheses

\begin{tabular}{ll}
\hline S/ No. & Hypothesis \\
\hline $\mathrm{H}_{01}$ & Domestic knowledge has a positive relationship with knowledge acquisition \\
$\mathrm{H}_{02}$ & Market knowledge has a positive relationship with knowledge acquisition \\
$\mathrm{H}_{03}$ & Technological knowledge has a positive relationship with knowledge acquisition. \\
$\mathrm{H}_{04}$ & Environmental knowledge has a positive relationship with knowledge acquisition. \\
\hline
\end{tabular}

The hypotheses are summarized in the diagram below: Fig. 2

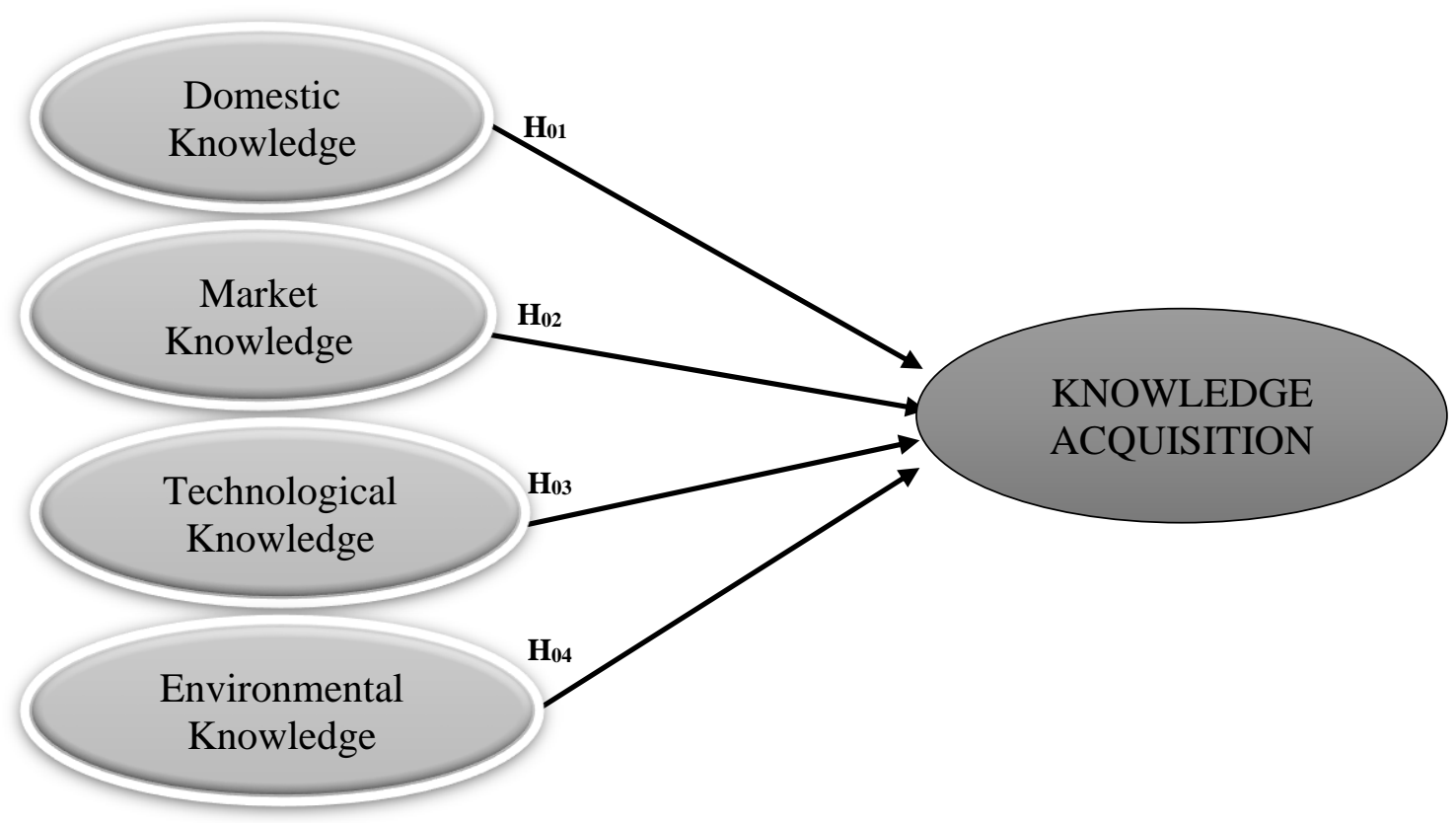

Fig. 2. Model for Paper

\section{PROPOSED EMPIRICAL TEST}

To test the above hypotheses, an empirical study is proposed. A survey will be utilized to collect data on the antecedent factors i.e. domestic, market, technological and environmental knowledge and the dependent variable which is knowledge acquisition. With the quantitative methodology, primary data will be collected utilizing the faceto-face administration of questionnaires. The aim is to test the theoretically developed hypotheses about the effects among a set of study variable constructs, and also the use of validity and reliability to evaluate the findings so that they could be generalized. On this front, the researcher will take into consideration the tenets of positivism philosophy. Structural equation modeling using Smart PLS would be used to analyze the data. 


\section{CONCLUSION}

Premised on the discussions so far, it can be inferred that the acquiring of organizational knowledge is indeed a multifaceted function, represented in domestic, market, technological and environmental knowledge, with the presence of the theoretically deduced dimensions which can be objectively proven. Also, the use of a quantitative survey to test organizational phenomena and the subsequent analyses of claims relating to the acquisition of knowledge can become objective. Moreover, by integrating multiple variables, the capacity to form the interaction among the aforementioned factors constitutes another significant source of knowledge acquisition for the firms to explore.

\section{Acknowledgements}

This research work is financially supported by Dr. Norzaidahwati Zaidin

\section{Reference:}

Afriyie, S., Duo, J., Appiah, K., \& Musah, A. I. (2018). The Nexus between Types of Innovation and Marketing Performance of Small Medium-sized Enterprises in an Emerging Economy, (April 2019). https://doi.org/10.32479/irmm.7042

Anatoliivna, V. O. (2013). Absorptive capacity in organizational theories: learning, innovation, managerial cognition, 190-198.

Argote, L., \& Miron-spektor, E. (2011). Organizational Learning: From Experience to Knowledge, 22(5), 1123-1137.

Baker, michael J. (n.d.). No Title.

Barney, J. B. (2001). Resource-based theories of competitive advantage: A ten- year retrospective on the resource-based view, 27, 643-650.

Basten, D., \& Haamann, T. (2018). Approaches for Organizational Learning: A Literature Review. https://doi.org/10.1177/2158244018794224

Bennet, D. H., \& Bennet, A. (n.d.). Metaknowledgetoactions.

Bojica, A. M., \& Fuentes-fuentes, M. M. (2019). Knowledge Acquisition and Corporate Entrepreneurship: Insights from Spanish SMEs in the ICT Sector, (July 2012). https://doi.org/10.1016/j.jwb.2011.05.007

Bojica, A. M., \& Fuentes, M. del M. F. (2012). Knowledge acquisition and corporate entrepreneurship: Insights from Spanish SMEs in the ICT sector. Journal of World Business. https://doi.org/10.1016/j.jwb.2011.05.007

Camisón-Haba, S., Clemente-Almendros, J. A., \& Gonzalez-Cruz, T. (2019). How technology-based firms become also highly innovative firms? The role of knowledge, technological and managerial capabilities, and entrepreneurs' background. Journal of Innovation and Knowledge. https://doi.org/10.1016/j.jik.2018.12.001

Cohen, W. M., \& Levinthal, D. A. (1990). Absorptive Capacity: A New Perspective on Learning and Innovation Wesley M. Cohen; Daniel A . Levinthal Absorptive Capacity : A New Perspective on Learning and Innovation, 35(1), 128-152. 
Crescenzi, R., \& Gagliardi, L. (2018). The innovative performance of firms in heterogeneous environments: The interplay between external knowledge and internal absorptive capacities. Research Policy. https://doi.org/10.1016/j.respol.2018.02.006

Curado, C. (2014). THE KNOWLEDGE BASED-VIEW OF THE FIRM: FROM THEORETICAL ORIGINS, (January 2006).

Evangelista, F., \& Mac, L. (2016). The influence of experience and deliberate learning on SME export performance. https://doi.org/10.1108/JJEBR-12-2015-0300

Góra, Z., \& Góra, Z. (2017). THE ROLE OF KNOWLEDGE ACQUISITION IN A COMPANY $\mathrm{R}$ RESEARCH RESULTS FROM GERMAN AND POLISH MANUFACTURING COMPANIES Justyna PATALASMALISZEWSKA *, Ma † gorzata Ś LIWA **, 9, 87-98. https://doi.org/10.1515/fman-2017-0007

Hailikari, T., Katajavuori, N., \& Lindblom-Ylanne, S. (2008). The Relevance of Prior Knowledge in Learning and Instructional Design. American Journal of Pharmaceutical Education, 72(5), 1-113. Retrieved from http://library.capella.edu/login?qurl=https\%3A\%2F\%2Fsearch.proquest.com\%2Fdocview\% 2F211262978\%3Faccountid\%3D27965

Hamdoun, M., Chiappetta Jabbour, C. J., \& Ben Othman, H. (2018). Knowledge transfer and organizational innovation: Impacts of quality and environmental management. Journal of Cleaner Production. https://doi.org/10.1016/j.jclepro.2018.05.031

Harrigan, K. R., Di Guardo, M. C., \& Cowgill, B. (2017). Multiplicative-innovation synergies: tests in technological acquisitions. Journal of Technology Transfer, 42(5), 1212-1233. https://doi.org/10.1007/s10961-016-9514-3

He, W., Zhang, W., Tian, X., Tao, R., \& Akula, V. (2018). Identifying customer knowledge on social media through data analytics, (2001). https://doi.org/10.1108/JEIM-02-2018-0031

Huber, G. P., Science, O., Issue, S., \& Learning, O. (2014). Organizational Learning: The Contributing Processes and the Literatures Organizational Learning: The Contributing Processes and the Literatures, (December). https://doi.org/10.1287/orsc.2.1.88

Huggins, R., Prokop, D., \& Thompson, P. (2017). Entrepreneurship and the determinants of firm survival within regions: human capital, growth motivation and locational conditions. Entrepreneurship and Regional Development, 29(3-4), 357-389. https://doi.org/10.1080/08985626.2016.1271830

Jiménez-jiménez, D., \& Sanz-valle, R. (2011). Innovation, organizational learning, and performance. Journal of Business Research, 64(4), 408-417. https://doi.org/10.1016/j.jbusres.2010.09.010

Johnson, M. P. (2017). Knowledge acquisition and development in sustainability-oriented small and medium-sized enterprises: Exploring the practices, capabilities and cooperation. Journal of Cleaner Production. https://doi.org/10.1016/j.jclepro.2016.10.087

Kaplan, S., \& Schenkel, A. (2001). Knowledge-Based Theories of the Firm in Strategic Management : A Review and Extension, (November 2013).

Katie, B., Milway, S., \& Saxton, A. (2011). The Challenge of Organizational Learning.

Kotler, P., \& Keller, K. L. (2012). Marketing Management.

Liao, Y., \& Barnes, J. (2015). Knowledge acquisition and product innovation flexibility in SMEs. Business Process Management Journal, 21(6), 1257-1278. https://doi.org/10.1108/BPMJ-05-20140039

Liao, Y., Barnes, J., College, M., \& Carolina, N. (2015). Knowledge acquisition and product innovation flexibility in SMEs, 21(6), 1257-1278. https://doi.org/10.1108/BPMJ-05-2014-0039 
Lin, H., Chen, M., \& Su, J. (2017). How management innovations are successfully implemented? An organizational routines' perspective. Journal of Organizational Change Management, 30(4), 456-486. https://doi.org/10.1108/JOCM-07-2016-0124

Long, X., Chen, Y., Du, J., Oh, K., \& Han, I. (2017). Environmental innovation and its impact on economic and environmental performance: Evidence from Korean-owned firms in China. Energy Policy, 107(September), 131-137. https://doi.org/10.1016/j.enpol.2017.04.044

Mahmoud, M. A., Blankson, C., Owusu-frimpong, N., Nwankwo, S., Tran, P., Mahmoud, M. A., ... Mahmoud, M. A. (2016). Market orientation, learning orientation and business performance The mediating role of innovation. https://doi.org/10.1108/IJBM-04-2015-0057

Mehralian, G., Nazari, J. A., \& Ghasemzadeh, P. (2018). The effects of knowledge creation process on organizational performance using the BSC approach: the mediating role of intellectual capital. Journal of Knowledge Management, 22(4), 802-823. https://doi.org/10.1108/JKM10-2016-0457

MILLER, C. D., \& TOH, P. K. (2018). COMPLEMENTARY TECHNOLOGIES AND RETURNS TO DISCLOSURE DURING STANDARD SETTING CAMERON. Clinical Teacher, 12(4), 226-230. https://doi.org/10.1111/tct.12395

Mohannak, K. (2014). Knowledge Management \& E-Learning, 6(1), 66-82.

Moorthy, S., \& Polley, D. E. (2010). Technological knowledge breadth and depth: Performance impacts. Journal of Knowledge Management, 14(3), 359-377. https://doi.org/10.1108/13673271011050102

Noblet, J., Simon, E., \& Parent, R. (2011). Absorptive capacity : a proposed operationalization, 9(4), 367377. https://doi.org/10.1057/kmrp.2011.26

Nonaka, I., \& Lewin, A. Y. (2011). Dynamic Theory Knowledge of Organizational Creation, 5(1), 14-37.

OECD. (2007). SMALL BUSINESSES AND ENVIRONMENTAL Review and Possible Application of International Experience in Georgia. Environment. https://doi.org/10.1111/j.17456584.2011.00822.x

Oslo Manual, O. (2018). Oslo Manual 2018.

Pantano, E., Priporas, C. V., Sorace, S., \& lazzolino, G. (2017). Does innovation-orientation lead to retail industry growth? Empirical evidence from patent analysis. Journal of Retailing and Consumer Services. https://doi.org/10.1016/j.jretconser.2016.10.001

Pazzani, J., Banalou, L., Hampton, J., Rou, B., Shulq, T., Silverstein, G., ... Palmer, L. (1989). Influence of Prior Knowledge on Concept Acquisition : Experimental and Computational Results.

Pentina, I. (2018). Organizational Learning and New Product Outcomes: Integrating Research Approaches. https://doi.org/10.1007/978-3-319-11761-4

Ramaiah, C. K. (2019). Measuring Knowledge Acquisition and Knowledge Creation: a Review of Measuring Knowledge Acquisition and Knowledge Creation : a Review of Literature 1, (April). https://doi.org/10.13140/RG.2.2.33416.67844

Rao, A. R., \& Monroe, K. B. (1988). The Moderating Effect of Prior Knowledge on Cue Utilization in Product Evaluations. Journal of Consumer Research, 15(2), 253. https://doi.org/10.1086/209162

Roper, S., Love, J. H., \& Bonner, K. (2017). Firms' knowledge search and local knowledge externalities in innovation performance. Research Policy. https://doi.org/10.1016/j.respol.2016.10.004 
Schaarschmidt, M., \& Walsh, G. (2018). Customer Interaction and Innovation in Hybrid Offerings: Investigating Moderation and Mediation Effects for Goods and Services Innovation, 21(1), 119-134. https://doi.org/10.1177/1094670517711586

Schot, J., \& Steinmueller, W. E. (2018). Three frames for innovation policy: R\&D, systems of innovation and transformative change. Research Policy, 47(9), 1554-1567. https://doi.org/10.1016/j.respol.2018.08.011

Shane, S. (n.d.). The 8th International Conference for Entrepreneurship, Innovation and Regional.

Song, M., Park, J.-O., \& Park, B. S. (2017). Determinants of R\&D Commercialization by SMEs after Technology Transfer. Asian Journal of Innovation and Policy, 6(1), 45-57. https://doi.org/10.7545/ajip.2017.6.1.045

Stephen, I. A., Oluseye, O. O., \& Abolaji, A. J. (2017). Extending the knowledge strategy concept: Linking organizational knowledge with strategic orientations. Academy of Strategic Management Journal, 16(3), 1-11.

Storey, C., \& Larbig, C. (2018). Absorbing Customer Knowledge: How Customer Involvement Enables Service Design Success, 21(1), 101-118. https://doi.org/10.1177/1094670517712613

Subbanarasimha, P. N., Ahmad, S., \& Mallya, S. N. (2003). Technological knowledge and firm performance of pharmaceutical firms. Journal of Intellectual Capital, 4(1), 20-33. https://doi.org/10.1108/14691930310455360

Taghizadeh, S. K., Rahman, S. A., \& Hossain, M. (2018). Knowledge from customer, for customer or about customer: which triggers innovation capability the most?, 22(1), 162-182. https://doi.org/10.1108/JKM-12-2016-0548

Venkitachalam, K., Busch, P., Venkitachalam, K., \& Busch, P. (2012). Tacit knowledge : review and possible research directions. https://doi.org/10.1108/13673271211218915

Vrontis, D., Thrassou, A., Santoro, G., \& Papa, A. (2017). Ambidexterity, external knowledge and performance in knowledge-intensive firms. Journal of Technology Transfer, 42(2), 374-388. https://doi.org/10.1007/s10961-016-9502-7

Wang, Y., \& Wang, Y. (2016). Learning and innovation in small and medium enterprises, (March 2010). https://doi.org/10.1108/02635571011020296

Waribugo, S., Wilson, O. C., \& Etim, E. (2016). The Impact of Knowledge Management on Product Innovation of Manufacturing Firms in Nigeria, 6(6), 78-87.

Xie, R. hui, Yuan, Y. jun, \& Huang, J. jing. (2017). Different Types of Environmental Regulations and Heterogeneous Influence on "Green" Productivity: Evidence from China. Ecological Economics. https://doi.org/10.1016/j.ecolecon.2016.10.019

Xie, X., Wang, L., \& Zeng, S. (2018). Inter-organizational knowledge acquisition and firms' radical innovation: A moderated mediation analysis. Journal of Business Research. https://doi.org/10.1016/j.jbusres.2018.04.038

Xie, X., Zou, H., \& Qi, G. (2018). Knowledge absorptive capacity and innovation performance in hightech companies: A multi-mediating analysis. Journal of Business Research. https://doi.org/10.1016/j.jbusres.2018.01.019

Yachin, J. M. (2018). The 'customer journey': Learning from customers in tourism experience encounters. Tourism Management Perspectives. https://doi.org/10.1016/j.tmp.2018.09.002

Yu, B., \& Shen, C. (2020). Environmental regulation and industrial capacity utilization: An empirical study of China. Journal of Cleaner Production. https://doi.org/10.1016/j.jclepro.2019.118986

Zhou, W., Hu, H., \& Shi, X. (2015). The Learning Organization Article information : 